University of Nebraska - Lincoln

DigitalCommons@University of Nebraska - Lincoln

Faculty Publications: Department of Entomology

Entomology, Department of

June 2004

Postlarval Fitness of Transgenic Strains of Cochliomyia

hominivorax (Diptera: Calliphoridae)

Margaret L. Allen

USDA-ARS

Dennis Berkebile

USDA-ARS, DENNIS.BERKEBILE@ars.usda.gov

Steven R. Skoda

USDA-ARS

Follow this and additional works at: https://digitalcommons.unl.edu/entomologyfacpub

Part of the Entomology Commons

Allen, Margaret L.; Berkebile, Dennis; and Skoda, Steven R., "Postlarval Fitness of Transgenic Strains of Cochliomyia hominivorax (Diptera: Calliphoridae)" (2004). Faculty Publications: Department of Entomology. 25.

https://digitalcommons.unl.edu/entomologyfacpub/25

This Article is brought to you for free and open access by the Entomology, Department of at DigitalCommons@University of Nebraska - Lincoln. It has been accepted for inclusion in Faculty Publications: Department of Entomology by an authorized administrator of DigitalCommons@University of Nebraska - Lincoln. 


\title{
Postlarval Fitness of Transgenic Strains of Cochliomyia hominivorax (Diptera: Calliphoridae)
}

\author{
MARGARET L. ALLEN, DENNIS R. BERKEBILE, AND STEVEN R. SKODA ${ }^{1}$ \\ Midwest Livestock Insects Research Unit, USDA-ARS, 305 Plant Industry Building, University of Nebraska East Campus, \\ Lincoln, NE 68583
}

J. Econ. Entomol. 97(3): 1181-1185 (2004)

\begin{abstract}
Eight transgenic strains of Cochliomyia hominivorax (Coquerel) (Diptera: Calliphoridae) were compared with the wild-type parental laboratory strain (P95) in colony. Measurements of average weight of pupae, percentage of adults emerging from pupae, ratio of males to total emerged adults, and mating competitiveness were analyzed. The parental strain colony was subcultured and exposed to handling procedures equivalent to transgenic strains for valid comparison of overall colony fitness. None of the transgenic colonies exhibited significantly lower fitness characteristics than the control parental colony. One transgenic colony had a higher ratio of adults emerging from pupae, and five colonies had higher average pupal weight; because fitness cost would only be indicated by lower values, the statistical variations were not significant. Males of one transgenic strain were shown to mate with equal frequency compared with males of the parental strain. Hence, the presence of the transgene used to produce the strains tested did not incur a fitness cost to the colonies of laboratory-reared $C$. hominivorax.
\end{abstract}

KEY WORDS Cochliomyia hominivorax, New World screwworm, fitness, transgenic insect, sterile insect technique

TRANSGENIC INSECTS HAVE BEEN proposed as an improvement to current sterile insect technique (SIT) programs (Handler 2002). SIT programs involve the mass release of laboratory-reared, sterilized insects into the environment. Some key issues involved in mass release of sterile insects relate to fitness of released insects, including mating competence and competitiveness (Knipling 1955). Transgenic insects must be equally capable of surviving and mating with wild insects to be effective. Also, the fitness of the immatures must be equivalent or better than the current production strain if they are to be successfully used in mass production. Therefore, it is critical to analyze fitness characteristics of transgenic insects.

The New World screwworm, Cochliomyia hominivorax (Coquerel) (Diptera: Calliphoridae), was the first insect controlled using SIT (Wyss 2000). The New World Screwworm Eradication Program successfully eliminated C. hominivorax from the North American continent, but this species remains endemic in South America and the Caribbean. The eradication zone has progressed to the Darien Gap in Panama, where flies that have been sterilized using ionizing radiation are

Mention of tradenames or commercial products in this article is solely for the purpose of providing specific information and does not imply recommendation or endorsement by the U.S. Department of Agriculture.

${ }^{1}$ USDA-ARS Screwworm Research Unit 0945, APO AA 34002 , Panama City, Panama. currently released to prevent reinvasion of the northern continent.

Transgenic organisms may persist once released, and they pose the risk of hazards above and beyond the pest problems they were intended to control (Muir and Howard 1999, 2002; Daniell 2002). This could occur by a failure in the transgenic insect, for example, by mutation or remobilization of the transgene (Pew Initiative 2004). Furthermore, a failure in the production system could result in inadvertent release of fertile insects, a hazard in current sterile insect release programs. Assessment of risk requires a baseline of data on relative fitness of transgenic insects compared with "wild-type" laboratory-reared counterparts for extrapolative comparison with true wild populations. Thus, fitness analyses serve both to evaluate the potential success of a laboratory-reared insect strain for use in SIT and potential environmental risks of released genetically modified organisms. Components of this essential data set, presented here, are average pupal weight, overall adult emergence from pupae, male/female ratio, and mating competition.

\section{Materials and Methods}

Insect Stocks. The Midwest Livestock Insects Research Unit has established several distinct strains of transgenic New World screwworm (Allen et al. 2004) incorporating an enhanced green fluorescent protein 
Table 1. Comparison of wild-type strains of New World screwworm reared with (XG) and without simulated transgenic screening (examination as crawlers in ultraviolet illumination)

\begin{tabular}{|c|c|c|c|c|c|c|c|c|}
\hline Wild-type strain & Avg pupal wt. & $\begin{array}{c}\text { Avg pupal wt. } \\
\text { LSME }\end{array}$ & SE & Difference of LSME & SE & df & $t$ Value & $P>|t|$ \\
\hline CR91 & 3.829 & 3.8134 & 0.05285 & & & & & \\
\hline CR91XG & 3.998 & 4.0448 & 0.06226 & $-0.2314 *$ & 0.08155 & 83 & -2.84 & 0.0057 \\
\hline P95 & 4.042 & 4.0423 & 0.04596 & & & & & \\
\hline P95XG & 4.106 & 4.1450 & 0.06092 & -0.1027 & 0.07631 & 83 & -1.35 & 0.1819 \\
\hline Wild-type strain & $\begin{array}{l}\% \text { Adult } \\
\text { emergence }\end{array}$ & $\begin{array}{l}\text { \% Adult } \\
\text { emergence } \\
\text { LSME }\end{array}$ & SE & Difference of LSME & SE & df & $t$ Value & $P>|t|$ \\
\hline CR91 & 90.4 & 90.0189 & 1.15890 & & & & & \\
\hline CR91XG & 86.6 & 90.7149 & 1.36880 & -0.6960 & 1.7921 & 82 & -0.39 & 0.6987 \\
\hline P95 & 90.6 & 90.6000 & 1.00750 & & & & & \\
\hline P95XG & 85.7 & 89.7918 & 1.36880 & 0.8082 & 1.6996 & 82 & 0.48 & 0.6357 \\
\hline Wild-type strain & Avg male ratio & $\begin{array}{l}\text { Avg ratio } \\
\text { LSME }\end{array}$ & SE & Difference of LSME & SE & df & $t$ Value & $P>|t|$ \\
\hline CR91 & 0.5036 & 0.4974 & 0.01169 & & & & & \\
\hline CR91XG & 0.4841 & 0.4845 & 0.01380 & 0.0129 & 0.01807 & 82 & 0.72 & 0.4765 \\
\hline P95 & 0.5102 & 0.5102 & 0.01016 & & & & & \\
\hline P95XG & 0.5013 & 0.5016 & 0.00138 & 0.0086 & 0.01714 & 82 & -0.50 & 0.6191 \\
\hline
\end{tabular}

LSME, least squares means estimate.

* Significantly different from control.

(EGFP) marker. Transgenic strains were generated by microinjecting embryos with piggyBac helper and vector plasmids. Injected embryos were reared and crossed to the parental strain, and the offspring were screened for expression of the fluorescent EGFP marker. Putative transgenic founder insects were outcrossed for several generations to establish phenotypically distinct strains. These strains were then reared over several generations to achieve sufficient numbers to establish colonies, and colonies were selected for consistent EGFP expression patterns. Molecular analysis of each stable strain indicated at least a single copy of the transgene incorporated into distinct genomic locations (Allen et al. 2004). These strains were used to assess the fitness costs associated with genomic transgene integration. Laboratory colonies of "wildtype" New World screwworm strains, also maintained in the Midwest Livestock Insects Research Unit New World Screwworm BioSecure Facility were used for comparison and crossing.

All transgenic $C$. hominivorax colonies were derived from the P95 strain, which was collected from Panama and was the most current strain used in the SIT program. Insects were reared according to USDA-ARSand APHIS-established protocols (Melvin and Bushland 1936, Taylor et al. 1991). It is the policy of the New World Screwworm BioSecure Facility to maintain continuous overlapping generations as insurance against loss of strains (colony crash). Because the transgenic colonies were recently established, and because of logistic limitations, only one-half the number of overlapping generations of transgenics were maintained. The transgenic colonies were split between biweekly generation schedules.

Although insect rearing at the New World Screwworm BioSecure Facility was performed using established protocols, occasional fluctuations in rearing environment occur. However, each cohort of insects was processed as a group and exposed to the same fluctuations, because they were in the same incubators and were handled by the same people. Transgenic colonies of New World screwworm required some modified procedures. Because the verification of transgenic status was through visualization of the fluorescent protein marker (pUbnlsEGFP), each strain was screened by examination with UV illumination before pupation. The pupal and imaginal cuticles are completely opaque, making screening of these stages impossible without destruction of the insect. For each transgenic strain, fully mature (crawler) third instars were separated from rearing medium and examined each generation. This procedure was usually performed on one day (5 day) during the development of each cohort of insects. Unscreened pupae were discarded. Standard rearing practices of nontransgenic strains allow insects to pupate unmolested for several days, with pupae collected on day 9 or 10. A much smaller portion of pupae was collected for each generation from the transgenic colonies; thus, a smaller number of transgenic adults were available to produce eggs. Furthermore, the screening process of transgenic insects was nonrandom because the smaller larvae were discarded in favor of larger specimens. To provide equal conditions for transgenic and nontransgenic parental colonies, a subculture colony of wildtype P95 insects was established. This colony, P95XG, was screened in the same manner as the transgenic colonies, including discarding smaller individuals. For validation, a second wild-type laboratory New World screwworm colony, CR91, a strain established in 1991 from insects collected in Costa Rica and used for a short time as the SIT strain, was established and handled in the same manner and identified as CR91XG.

Fitness Measurements. Fitness parameters measured on a continuing basis at the New World Screwworm BioSecure Facility include egg production, egg 
Table 2. Postlarval fitness characteristics of transgenic strains of New World screwworm compared with control

\begin{tabular}{|c|c|c|c|c|c|c|c|c|}
\hline \multicolumn{9}{|c|}{ A. Comparison of average pupal weights of transgenic strains to parental (P95XG) strain of NWS } \\
\hline Strain & Avg pupal wt. & Avg pupal wt. LSME & $\mathrm{SE}$ & $\begin{array}{l}\text { Difference of } \\
\text { LSME }\end{array}$ & SE & df & $t$ Value & $P>|t|$ \\
\hline GARY & 4.132 & 4.0473 & 0.06517 & -0.09385 & 0.09555 & 265 & -0.98 & 0.3269 \\
\hline P95XG (control) & 4.106 & 4.1411 & 0.07231 & & & & & \\
\hline CLOX & 4.284 & 4.2105 & 0.06407 & 0.06942 & 0.09494 & 265 & 0.73 & 0.4653 \\
\hline CLAY & 4.294 & 4.2432 & 0.05978 & 0.10210 & 0.09216 & 265 & 1.11 & 0.2690 \\
\hline FOLY & 4.442 & 4.3969 & 0.06173 & $0.25580 *$ & 0.09417 & 265 & 2.72 & 0.0070 \\
\hline COTY & 4.431 & 4.4588 & 0.06114 & $0.31770^{*}$ & 0.09432 & 265 & 3.37 & 0.0009 \\
\hline SUEZ & 4.466 & 4.5204 & 0.05392 & $-0.37930 *$ & 0.09128 & 265 & -4.16 & $<.0001$ \\
\hline CLIX & 4.474 & 4.5501 & 0.06113 & $0.40890 *$ & 0.09622 & 265 & 4.25 & $<.0001$ \\
\hline GIZA & 4.731 & 4.7836 & 0.05580 & $0.64250 *$ & 0.09208 & 265 & 6.98 & $<.0001$ \\
\hline \multicolumn{9}{|c|}{ B. Comparison of adult emergence from pupation of transgenic strains to parental (P95XG) strain of NWS } \\
\hline Strain & $\%$ Adult emergence & \% Adult emergence LSME & SE & $\begin{array}{l}\text { Difference of } \\
\text { LSME }\end{array}$ & SE & df & $t$ Value & $P>|t|$ \\
\hline CLIX & 83.3 & 84.2161 & 1.9280 & -3.3492 & 2.6431 & 137 & -1.27 & 0.2072 \\
\hline GARY & 83.6 & 83.5189 & 2.2603 & -4.0465 & 2.5753 & 137 & -1.57 & 0.1184 \\
\hline CLOX & 85.1 & 85.5925 & 2.3056 & -1.9728 & 2.6216 & 137 & -0.75 & 0.4530 \\
\hline P95XG (control) & 89.0 & 87.5654 & 1.6391 & 1 & & & & \\
\hline COTY & 89.0 & 88.2339 & 2.1005 & 0.6686 & 2.6702 & 137 & 0.25 & 0.8027 \\
\hline FOLY & 90.5 & 91.3988 & 2.2970 & 3.8334 & 2.6178 & 137 & 1.46 & 0.1454 \\
\hline SUEZ & 91.0 & 91.1753 & 2.1559 & -3.6099 & 2.7520 & 137 & -1.31 & 0.1918 \\
\hline CLAY & 91.7 & 91.2752 & 2.0632 & 3.7098 & 2.4631 & 137 & 1.51 & 0.1343 \\
\hline GIZA & 93.3 & 93.0636 & 2.1628 & $5.4982 *$ & 2.7126 & 137 & 2.03 & 0.0446 \\
\hline \multicolumn{9}{|c|}{ C. Comparison of male ratio of transgenic strains to parental (P95XG) strain of NWS } \\
\hline Strain & Avg male ratio & Avg male ratio LSME & $\mathrm{SE}$ & $\begin{array}{l}\text { Difference of } \\
\text { LSME }\end{array}$ & SE & df & $t$ Value & $P>|t|$ \\
\hline FOLY & 0.497 & 0.4702 & 0.02249 & -0.02836 & 0.02563 & 137 & -1.11 & 0.2705 \\
\hline SUEZ & 0.498 & 0.5324 & 0.02111 & -0.03381 & 0.02694 & 137 & -1.25 & 0.2117 \\
\hline P95XG (control) & 0.501 & 0.4986 & 0.01605 & & & & & \\
\hline CLIX & 0.504 & 0.5222 & 0.01888 & 0.02357 & 0.02588 & 137 & 0.91 & 0.3640 \\
\hline COTY & 0.514 & 0.5444 & 0.02057 & 0.04586 & 0.02614 & 137 & 1.75 & 0.0817 \\
\hline GIZA & 0.521 & 0.5488 & 0.02118 & 0.05024 & 0.02656 & 137 & 1.89 & 0.0606 \\
\hline CLOX & 0.531 & 0.5025 & 0.02257 & 0.00392 & 0.02567 & 137 & 0.15 & 0.8790 \\
\hline CLAY & 0.548 & 0.5212 & 0.02020 & 0.02263 & 0.02412 & 137 & 0.94 & 0.3496 \\
\hline GARY & 0.570 & 0.5411 & 0.02213 & 0.04250 & 0.02521 & 137 & 1.69 & 0.0941 \\
\hline
\end{tabular}

LSME, least squares means estimate; NWS, New World screwworm.

* Significantly different from control.

hatch, average and total pupal weight, adult emergence, and male/female ratio. These measurements are used to evaluate the overall health and fitness of each colony or strain. Once transgenic New World screwworm strains were considered established as stable colonies (minimum five generations), fitness measurements were recorded from these colonies along with the other strains. Random samples of 100 pupae were collected from each colony to calculate average pupal weight. These pupae were isolated and allowed to emerge in a separate container to calculate adult emergence. The adults were then sexed and male ratio calculated.

For mating competitiveness, adult insects were isolated by sex upon adult emergence. Five-day-old insects were combined in mating cages, and eggs were collected between 1 and 3 days later. All collected eggs were reared. A random sample of 200 crawlers was examined for fluorescence for each replicate.

Statistical Analysis. The fitness measurements of pupal weight, adult emergence, and male ratio were analyzed with the MIXED Procedure (SAS Institute 1999), which compares least squares means. A probability of $<0.05$ was assigned as significant. The MIXED procedure accommodated the unequal sam- pling of colonies and provided for separation of evaluation of effects based on date and strain. Mating competition measurements were compared using a paired Student's $t$-test.

\section{Results and Discussion}

To evaluate the nonrandom handling impact incurred by fluorescent screening, two wild-type control colonies were compared (Table 1). The analyses of both adult emergence and male ratio did not yield significant differences for the threshold value of $P<$ 0.05 . For the pupal weight, a significant effect based on strain $(P=0.0006 ; \mathrm{df}=3,83 ; F=6.4)$ and not on date $(P=0.5197 ; \mathrm{df}=39,83 ; F=0.98)$ was detected; the CR91XG pupae were heavier than CR91 pupae. This indicated that the screening process was selective for heavier pupae probably because of the practice of discarding smaller specimens.

Based on observations of the transgenic colonies, fitness characteristics similar to the parental wild-type strain P95XG subculture were anticipated. All gross visual characteristics of the flies at all stages seemed identical; colonies were robust and vigorous. There- 


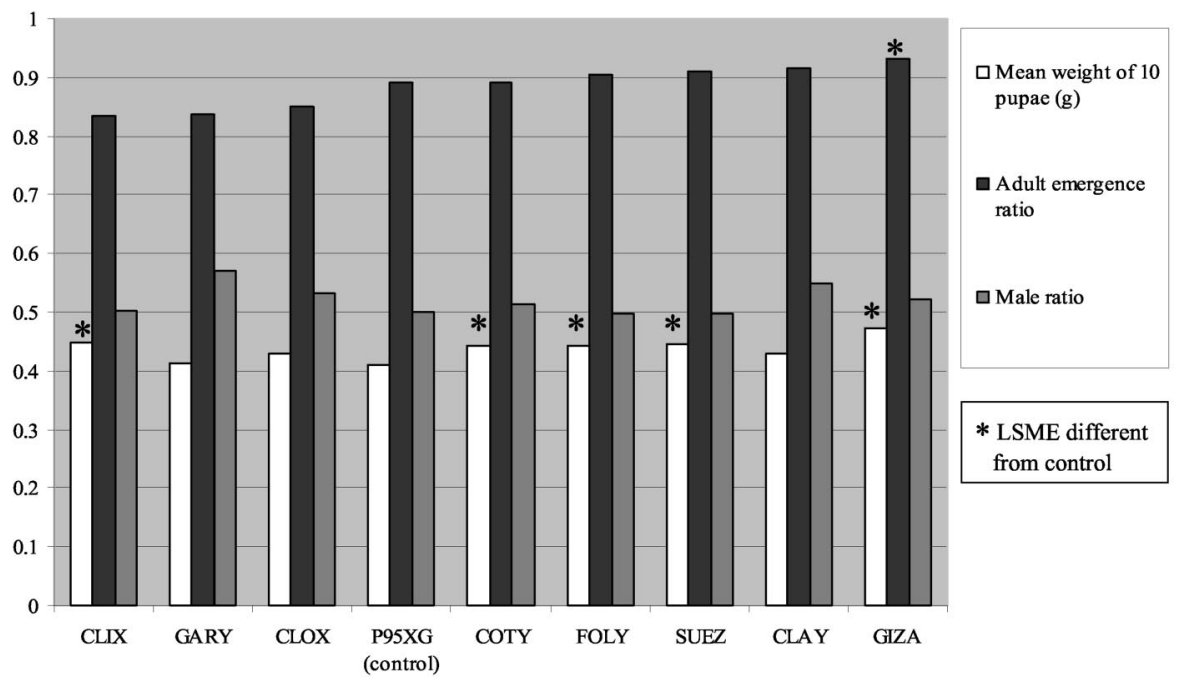

Strain

Fig. 1. Transgenic C. hominivorax strains exhibit postlarval fitness characteristics that compare favorably with the parental control strain P95XG. Average weight of pupae is adjusted to weight of 10 rather than 100 for better visibility with other chart values. Statistical variations from the control are indicated; however, because these values do not reflect fitness cost, they are not significant.

fore, we hypothesized that the transgenic element insertion did not incur a fitness cost to the colonies.

Average pupal weights of transgenic strains were compared with the parental New World screwworm strain, P95XG (Table 2A, illustrated in Fig. 1). Although differences were detected in five strains, FOLY, COTY, SUEZ, CLIX, and GIZA, pupal weights of the transgenic strain colonies were higher than those of the wild-type P95XG strain. An overall trend among the transgenic strains was higher pupal weight compared with controls. Pupal weight is considered a primary indicator of the health and fitness of New World screwworm colonies, so this comparison of transgenic strains to the parental P95 strain indicated that the fluorescent transgene conferred no fitness cost. As indicated in the control comparisons (Table 1) the transgenic screening process tends to select for heavier pupae, and the tendency for heavier pupae in transgenic strains may be attributed to handling.

Adult emergence ratio comparisons (Table 2B; illustrated in Fig. 1) produced only one strain comparison that met the set criterion for significant difference from the P95XG control. The GIZA strain differed statistically from P95XG, but again the difference was not an indication of fitness cost. Both strain $(P=$ $0.0001 ; \mathrm{df}=8,137 ; F=4.3)$ and date $(P<0.0001 ; \mathrm{df}=$ $55,137 ; F=3.03)$ effects were significant for the adult emergence analysis.

Male ratio comparisons did not indicate any strains that met the set criterion for significant difference from control. The date effect $(P<0.0242, \mathrm{df}=55 / 137$, $F=1.53)$ was significant within assigned constraints, but strain $(P=0.0836, \mathrm{df}=8 / 137, F=1.79)$ was not.

Mating competitiveness will be critical to the success of any transgenic strain used for SIT. The fluo- rescent marker in transgenic New World screwworm strains provided a convenient mechanism for evaluating mating competitiveness in a cage containing wild-type females and combined transgenic and wildtype males. Eggs produced by the females were reared, and a representative sample of the surviving larvae was screened for fluorescence. A homozygous transgenic male will father all fluorescent offspring, and a wild-type male's offspring will all be wild type. Assuming that the male transgenics are indeed homozygous for the transgene, and that egg production, hatch rate, and larval survival are not affected by the transgenic male, comparison of the fluorescence expression of crawlers would indicate the percentage of females successfully mated by transgenic males. We performed such a study using the transgenic strain CLAY and the P95 wild-type strain (Table 3). Based on the assumptions and rationale described, the CLAY transgenic males were equally competitive with P95 males $(P=0.9480, \mathrm{df}=2)$.

This series of experiments comparing overall postlarval fitness and mating ability between transgenic and parental strain (P95) wild-type insects indicated

Table 3. Mating success of transgenic strain CLAY males compared with control (P95, parental strain)

\begin{tabular}{|c|c|c|c|c|c|c|c|}
\hline \multicolumn{4}{|c|}{ Adult mating cages } & \multicolumn{4}{|c|}{ EGFP-expressing offspring } \\
\hline & $\begin{array}{l}\text { CLAY } \\
\text { males }\end{array}$ & $\begin{array}{c}\text { P95 } \\
\text { males }\end{array}$ & $\begin{array}{c}\text { P95 } \\
\text { females }\end{array}$ & & + & - & Ratio \\
\hline Week 1 & 25 & 25 & 75 & Week 1 & 74 & 126 & 0.37 \\
\hline Week 2 & 25 & 25 & 75 & Week 2 & 117 & 83 & 0.585 \\
\hline \multirow[t]{2}{*}{ Week 3} & 25 & 25 & 75 & Week 3 & 112 & 88 & 0.505 \\
\hline & & & & Total & 303 & 297 & 0.505 \\
\hline
\end{tabular}


that there was no loss of fitness in any strain of transgenic C. hominivorax. Specific strains showed some difference in average pupal weight and adult emergence, but these differences indicated no cost to fitness by rearing standards, and they were not associated with the existence of the transgene, but they were possibly due to a selective bottleneck (the generation of the transgenic strains).

Because nondrosophilid insect transformation is a relatively recent technology (Handler 2001), few transgenic insects have been evaluated for fitness characteristics. The production of eight colonies of transgenic New World screwworm strains with the same vector provided a unique system to evaluate fitness variations based on transformation technique and incorporation of a vector with no expected effect on overall traits. A fitness study using transgenic insects evaluated the persistence of transgenic Anopheles gambiae Giles mosquitoes over several generations. Whereas it was stated that longevity, feeding rate, larval development time, and egg-laying rate compared favorably with nontransgenics, population studies showed a decline of frequency and loss of the transgene allele over eight or fewer generations (Catteruccia et al. 2003). This type of study would be inappropriate for evaluating New World screwworm or other insects for SIT performance, but it would be valuable for environmental risk assessment. Transgenic New World screwworm will not be designed to replace an endemic population, but rather to eradicate the population by release of mass quantities of sterile individuals that mate and die. For this purpose, an insect that can compete is essential, and the results presented here are very supportive to that end.

Risk assessment research for any prospective New World screwworm transgenic strain for use in production should include evaluation of mating competition, longevity, flight performance, and transgene persistence and stability in the proposed strain(s). These kinds of studies could be used for predicting environmental hazards and planning outbreak control strategies.

A transgenic strain of New World screwworm that could be advantageous to the eradication program might be engineered in several ways. Simply incorporating a fluorescent marker into the laboratory strain would facilitate distinction of the laboratoryreared insects from truly wild insects and would be useful for monitoring purposes. Incorporating a conditional lethal genetic mechanism into the strain could prevent escaped laboratory insects from persisting in the wild, enhancing the security and safety of the program. If a conditional lethal could be linked to a sex-related genetic system it would be possible to eliminate female insects from the rearing and/or release process, enhancing production efficiency. If sterility could be engineered into a New World screwworm strain, it could be possible to eliminate the need for nuclear sterilization in the program (Alphey 2002, Allen et al. 2004). Regardless, a useful strain must be sufficiently fit for production-scale mass rearing. The decision to choose a particular strain to incorporate into implementation will require balanced evaluations of desired traits, prospective risks and costs, and expected benefits.

\section{Acknowledgments}

We thank the team of students and technicians, Brad Voelker, and Tony Weinhold (USDA-ARS Midwest Livestock Insects Research Unit BioSecure New World Screwworm Rearing Facility) for excellent assistance. Linda J. Young provided essential statistical analysis guidance. David Stanley and Stephen Danielson (University of NebraskaLincoln), and Phil Scholl (USDA-ARS Midwest Livestock Insects Research Unit) reviewed and provided helpful suggestions for the manuscript. This paper is No. 14309 of the Journal Series of the University of Nebraska Agricultural Research Division and Contribution no. 1165 of the Department of Entomology, University of Nebraska-Lincoln.

\section{References Cited}

Allen, M. L., A. M. Handler, D. R. Berkebile, and S. R. Skoda. 2004. piggyBac transformation of the New World screwworm, Cochliomyia hominivorax, produces multiple distinct mutant strains. Med. Vet. Entomol. 18: 1-9.

Alphey, L. 2002. Re-engineering the sterile insect technique. Insect Biochem. Mol. Biol. 32: 1243-1247.

Catteruccia, F., H. C. Godfray, and A. Crisanti. 2003. Impact of genetic manipulation on the fitness of Anopheles stephensi mosquitoes. Science (Wash DC) 299: 1225-1227.

Daniell, H. 2002. Molecular strategies for gene containment in transgenic crops. Nat. Biotech. 20: 581-586.

Handler, A. M. 2001. A current perspective on insect gene transformation. Insect Biochem. Mol. Biol. 31: 111-128.

Handler, A. M. 2002. Prospects for using genetic transformation for improved SIT and new biocontrol methods. Genetica 116: 137-149.

Knipling, E. F. 1955. Possibilities of insect control or eradication through the use of sexually sterile males. J. Econ. Entomol. 48: 459-462.

Melvin, R., and R. C. Bushland. 1936. The nutritional requirements of screwworm larvae. J. Econ. Entomol. 33: $850-852$.

Muir, W. M., and R. D. Howard. 1999. Possible ecological risks of transgenic organism release when transgenes affect mating success: sexual selection and the Trojan gene hypothesis. Proc. Natl. Acad. Sci. U.S.A. 96: 13853-13856.

Muir, W. M., and R. D. Howard. 2002. Assessment of possible ecological risks and hazards of transgenic fish with implications for other sexually reproducing organisms. Transgenic Res. 11: 101-114.

Pew Initiative. 2004. Bugs in the system? Issues in the science and regulation of genetically modified insects. In The Pew Initiative on Food and Biotechnology [ed.], www.pewagbiotech.org, Washington, DC.

SAS Institute. 1999. SAS OnlineDoc, version 8.01. SAS Institute, Cary, NC.

Taylor, D. B., J. C. Bruce, and R. Garcia. 1991. Gelled diet for screwworm (Diptera: Calliphoridae) mass production. J. Econ. Entomol. 84: 927-935.

Wyss, J. H. 2000. Screwworm eradication in the Americas. Ann. N.Y. Acad. Sci. 916: 186-193.

Received 14 November 2003; accepted 18 February 2004 